\title{
Treatment of Degenerated Intervertebral Discs Using a Viable Disc Tissue Allograft for Chronic Discogenic Low Back Pain: A Randomized Controlled Trial Comparing Single-site Outcomes With Aggregate and Longer-Term Follow-Up Data
}

Timothy Davis

Source Healthcare

Afrida Sara

Source Healthcare

Terry Nguyen

Source Healthcare.com

John Kenneth Burkus ( $\nabla$ jkb66@knology.net)

Hughston Clinic https://orcid.org/0000-0002-9619-4545

Research article

Keywords: discogenic back pain, allograft supplementation, degenerative disc disease, low back pain

Posted Date: November 9th, 2021

DOI: https://doi.org/10.21203/rs.3.rs-831525/v2

License: (c) (1) This work is licensed under a Creative Commons Attribution 4.0 International License. Read Full License 


\section{Abstract}

Background: Disruption of the internal structure of the nucleus pulposus commonly occurs with the development of painful degenerative lumbar disc disease. Supplementing disc tissue through autologous or allogeneic human cellular and tissue therapies has been tested in small sample clinical trials. A few investigators have reported substantial improvements in pain and function. A viable disc tissue allograft was developed to supplement tissue loss associated with intervertebral disc degeneration.

Methods: We assessed results in a subgroup of patients from a large trial comparing this allograft with other treatments. A multicenter randomized controlled trial of 218 subjects with chronic low back pain secondary to degenerative disc disease was conducted. Patients were treated with the allograft, saline, or nonsurgical management and studied for 12 months. We assessed longer-term results in a single-site subgroup from this prospective trial.

Results: At 12 months, subjects from the single-site subgroup who had been randomly assigned to the active allograft group ( $\mathrm{n}=17)$ showed improvements in both mean Oswestry Disability Index (ODI) and Visual Analog Scale (VAS) scores. There was an overall reduction of 28.69 points in the ODI and 33.06 points in the VAS. This was similar to the aggregate ODI and VAS scores of the active allograft group. At 24 months postprocedure, 9 of the 10 patients remaining in the active allograft group at the single study site had mean ODI and VAS score improvements of 28.23 and 36.13 , respectively. A similar improvement in pain scores occurred in the 4 patients at 36 months with mean ODI and VAS score improvements from preoperative scores of 25.21 and 51.35 , respectively.

Conclusions: Clinically meaningful improvements demonstrated in this single-site analysis were comparable to the aggregate study population at 12 months. Longer-term results from this single site at 24 and 36 months suggested durability of viable disc tissue allograft supplementation for patients with discogenic back pain.

Trial registration: The trial was retrospectively registered 17 October 2018 on www.clinicaltrials.gov (NCT03709901) and was approved by the Sterling Institutional Review Board, Atlanta, Georgia (IRB no. 5792).

\section{Background}

Disruption of the internal structure of the nucleus pulposus commonly occurs with the development of painful degenerative lumbar disc disease $[1,2]$. The nucleus contains a high concentration of proteoglycans; these specialized hydrophilic proteins contribute to the maintenance of intradiscal pressure that is essential to the mechanical function of the disc. The disc has a limited capacity for replenishing proteoglycans, and cumulative changes within the structure of the disc that occur over time with the loss of proteoglycans and cellular apoptosis represent the core of disc degeneration pathology [3]. Internal disc disruption results in the loss of functional tissue and altered biomechanics across the disc [4]. These progressive degenerative changes can initiate the symptoms associated with discogenic pain syndromes that are unrelated to sciatica or referred nerve root pain [5].

Supplementing disc tissue through autologous or allogeneic human cellular and tissue therapies has been tested in small sample clinical trials for the treatment of painful degenerative disc disease. A few trials have reported substantial improvements in pain and function [6-8]. Results from a larger prospective randomized trial using 
bone marrow-derived, expanded allogeneic mesenchymal stem cells (MSC) demonstrated improvements in pain and function [7]. Similarly, clinical studies using transplanted mesenchymal precursor cells have also shown promise $[9,10]$.

Treatment goals for chronic low back pain are to improve or restore function and alleviate pain, and clinical trial results address the safety and effectiveness of such a treatment. Commonly used patient-centered tools used to measure pain are based on numeric scales and validated condition-specific functional outcomes [11; however, mean changes in these questionnaire outcomes alone may not be clinically significant [12]. Minimum clinically important difference (MCID) has been advanced as a measure of a critical threshold needed to achieve treatment effectiveness [12-14]. Treatment effects reaching an MCID threshold value imply clinical significance and justification for implementation into clinical practice.

A multicenter prospective trial, the Viable Allograft Supplemented Disc Regeneration in the Treatment of Patients with Low Back Pain With or Without Disc Herniation (VAST) trial, provided no evidence that patients treated at sites with greater enrollment derived different therapeutic benefits $[15,16]$. To assess the durability of the viable disc allograft supplementation, a single site was selected to evaluate 24- and 36-month follow-up visits of the subjects initially enrolled in the VAST study. We compared the single-site outcomes to the overall study outcomes at these longer follow-up visits.

\section{Methods}

\section{Trial design}

Two hundred eighteen patients were enrolled in the trial across 13 sites and were followed from August 2017 to March $2020[15,16]$. Adult patients were included if they had 1 or 2 moderately degenerated lumbar intervertebral discs and had lower back symptoms present longer than 6 months that had not responded to nonoperative care. Radiographs, magnetic resonance imaging (modified-Pfirrmann disc degeneration grades 3 through 6), and physical examination were used to identify painful discs. Enrollment in the study was limited to patients with pre-treatment VAS score $\geq 40 \mathrm{~mm}$, Oswestry Disability Index (ODI) score $\geq$ 40, and Body Mass Index $(\mathrm{BMI})<35$.

Subjects who met all eligibility criteria were randomly assigned to 1 of 3 treatment arms with a 3.5:1:1 ratio: allograft treatment, saline (placebo) treatment, or nonsurgical management (NSM). Subjects who received either the allograft or saline returned for safety assessments and follow-up visits at 6 and 12 months after treatment transplant. The first 24 subjects who were randomized and enrolled across all sites returned for a 1-month follow up to assess safety before additional subjects were screened. Those in the nonsurgical care (NSM) group were evaluated at 3 months and provided an option of crossing over to receive the allograft treatment. They also returned for follow-up visits 6- and 12-months posttreatment. Co-primary outcomes of the trial were determined by assessment of ODI and Visual Analog Scale (VAS) score improvements at 12 months.

Subjects from the original randomized population signed new informed consent for optional follow up of 24 months and 36 months after their index procedure. Subjects from the allograft and saline groups were unblinded upon signing the new informed consent for the study extension. For the study extension, exploratory endpoints included durability of ODI scores and improvement in VAS scores 24 and 36 months after initial inclusion 
compared with 12-month improvement. Additional endpoints were improvement in SF-36, as well as hospitalization rate, re-operation rate, and resource utilization 24 and 36 months after treatment. All randomized subjects were given the option to receive allograft treatment at 24 months in accordance with the inclusion/exclusion re-evaluation. An MRI and x-ray were performed on subjects receiving another injection to evaluate changes in the disc. If needed, a second office visit was scheduled within 14 days of the original evaluation to allow appropriate time for the laboratory investigation and MRI. All follow-up subjects completed VAS, ODI, SF-36, and Resource Utilization questionnaires at both follow-up visits. The 36-month visit consisted of questionnaires and could be performed over the phone if the subject chose to do so.

MCID responder analysis was conducted to assess the clinical relevance of changes in scores of quality-of-life instruments and to identify the magnitude of change that the patient recognized as a major improvement.

\section{Statistical analysis}

The primary endpoints were the change in ODI and average back pain on the VAS at 12 months after treatment. The hypothesis for both the ODI and the VAS were: $\mathrm{H}_{0}: \tilde{\mathrm{x}} 1=\tilde{\mathrm{x}} 2=\tilde{\mathrm{x}} 3$, where $\tilde{\mathrm{x}} 1$ was the median pre-post difference in the active allograft group, $\tilde{\mathrm{x}} 2$ was the median pre-post difference in the saline group, and $\tilde{\mathrm{x}} 3$ was the median pre-post difference in the NSM group. The null hypothesis $(\mathrm{HO})$ for this endpoint states that there was no difference in change in ODI and VAS at 12 months among the 3 treatment groups. The alternative hypothesis $(\mathrm{Ha})$ was that there is a difference in change in the endpoints at 12 months among the 3 treatment groups.

For both the ODI and the VAS, the pre-post difference of the groups was compared using the Kruskal-Wallis test at a two-sided a-level of 0.05 . If the result for either test was significant, then the Dwass, Steel, Critchlow-Fligner Method was used to assess all pairwise comparisons for that endpoint.

Adverse event rates, serious adverse events rates, hospitalization rates, and re-operation rate were summarized by treatment group and compared using the chi-square test of independence or Fisher's exact test, as appropriate.

\section{Results}

\section{Study populations: Aggregate and Single Site}

The aggregate study initially enrolled 224 subjects; however, 6 subjects withdrew prior to receiving treatment, leaving 218 subjects. Thirty-six patients voluntarily withdrew or were lost to follow-up before their 12-month assessment. One hundred eighty-two subjects completed the 12-month visit across all sites. As previously reported, there were clinically meaningful improvements from baseline in the 2 co-primary endpoints (ODI and VAS at 12 months) in the overall study population, but differences between treatment groups did not reach significance [16].

At the single study site subgroup chosen for this analysis, 34 subjects were considered for the trial; however, 10 subjects were excluded prior to randomization due to voluntary withdrawal or lack of clinical imaging factors deemed necessary by the physician. Twenty-four subjects were successfully randomized into the active allograft, saline, or nonsurgical management (NSM) group, 1 subject withdrew from the trial before receiving the injection, 
and 1 subject from the NSM group was lost to follow-up after the 6-month mark. Twenty-three subjects (due to the crossover from the NSM group) were treated: 22 subjects completed all safety and imaging evaluations at baseline, and at 3 (NSM group only), 6, and 12 months.

Following randomization, 17 subjects received the active allograft, 2 received the saline, and 4 began in the nonsurgical management group. All 4 subjects in the NSM group met eligibility criteria for crossover and opted into the active treatment arm at the 3-month mark (Table 1). 
Table 1

Demographics and baseline characteristics

\begin{tabular}{|c|c|c|c|}
\hline & $\begin{array}{l}\text { Active allograft } \\
N=17\end{array}$ & $\begin{array}{l}\text { Saline } \\
N=2\end{array}$ & $\begin{array}{l}\text { NSM } \\
N=4\end{array}$ \\
\hline \multicolumn{4}{|l|}{ Age (years) } \\
\hline Mean $\pm S D(N)$ & $42.65 \pm 6.67$ & $46.50 \pm 16.26$ & $41.50 \pm 3.70$ \\
\hline \multicolumn{4}{|l|}{$\operatorname{Sex} n(\%)$} \\
\hline Female & $7(41.2)$ & $0(0.0)$ & $1(25.0)$ \\
\hline Male & $10(58.8)$ & $2(100.0)$ & $3(75.0)$ \\
\hline \multicolumn{4}{|l|}{ Race n $(\%)^{a}$} \\
\hline American Indian or Alaska Native & $1(5.9)$ & $0(0.0)$ & $0(0.0)$ \\
\hline Asian & $0(0.0)$ & $0(0.0)$ & $1(25.0)$ \\
\hline Black or African American & $0(0.0)$ & $0(0.0)$ & $0(0.0)$ \\
\hline Native Hawaiian or Pacific Islander & $0(0.0)$ & $0(0.0)$ & $0(0.0)$ \\
\hline White or Caucasian & $17(100.0)$ & $1(50.0)$ & $3(75.0)$ \\
\hline Other & $0(0.0)$ & $0(0.0)$ & $0(0.0)$ \\
\hline Not reported & $0(0.0)$ & $1(50.0)$ & $0(0.0)$ \\
\hline \multicolumn{4}{|l|}{ Ethnicity n (\%) } \\
\hline Hispanic & $0(.0 .0)$ & $1(50.0)$ & $0(0.0)$ \\
\hline Non-Hispanic & $17(100.0)$ & $1(50.0)$ & $4(100.0)$ \\
\hline \multicolumn{4}{|l|}{ Body Mass Index $\left(\mathrm{kg} / \mathrm{m}^{2}\right)$} \\
\hline Mean $\pm \mathrm{SD}(\mathrm{N})$ & $24.31 \pm 3.18(17)$ & $29.35 \pm 3.61(2)$ & $23.88 \pm 2.72(4)$ \\
\hline \multicolumn{4}{|l|}{ Smoking History n (\%) } \\
\hline Never & $11(64.7)$ & $1(50.0)$ & $3(75.0)$ \\
\hline Past smoker & $3(17.6)$ & $1(50.0)$ & $1(25.0)$ \\
\hline Current smoker & $3(17.6)$ & $0(0.0)$ & $0(0.0)$ \\
\hline Not reported & $0(0.0)$ & $0(0.0)$ & $0(0.0)$ \\
\hline \multicolumn{4}{|c|}{ History of Endocrine or Metabolic Disorders n (\%) } \\
\hline Yes & $1(5.9)$ & $0(0.0)$ & $0(0.0)$ \\
\hline No & $16(94.1)$ & $2(100.0)$ & $4(100.0)$ \\
\hline Not reported & $0(0 / 0)$ & $0(0 / 0)$ & $0(0.0)$ \\
\hline
\end{tabular}




\begin{tabular}{|llll|}
\hline & $\begin{array}{l}\text { Active allograft } \\
\mathbf{N}=\mathbf{1 7}\end{array}$ & $\begin{array}{c}\text { Saline } \\
\mathbf{N = \mathbf { 2 }}\end{array}$ & $\begin{array}{c}\text { NSM } \\
\mathbf{N = 4}\end{array}$ \\
\hline Levels of Treatment $\mathrm{n}(\%)$ & & \\
\hline One level & $7(41.2)$ & $0(0.0)$ & $2(50.0)$ \\
\hline Two levels & $10(58.87)$ & $2(100.0)$ & $2(50.0)$ \\
\hline a Subjects could report more than one race, so numbers may be greater than the total. \\
\hline
\end{tabular}

Following IRB approval of the extension for the 24- and 36-month follow-up visits, all subjects with 12 months of follow-up were re-contacted for further collection of patient-reported outcomes and evaluation for a second injection. The study was coincident with the COVID-19 pandemic, and although 13 subjects consented, with the necessity of in-person visits, only 10 successfully completed all required questionnaires, clinical imaging, and laboratory assessments. Of the 10 subjects who completed their in-person 24-month visit, 9 had received the active allograft and 1 had received the saline. One subject from the active allograft arm met all inclusion criteria and opted to receive a second allograft treatment for levels L2-L3 and L3-L4.

\section{Clinical Outcomes Sf-36}

The Short Form 36 (SF-36) Health Survey was used to assess general health status of all study patients. The SF36 measures specific health concepts related to physical functioning and limitations, social functioning, and health perceptions and can be summarized into 2 measures pertaining to mental health (MCS) and physical health (PCS).

In this study, both the mean MCS and PCS postoperative scores were higher than preoperative scores for both cohorts (Table 2). In the active allograft group, the mean PCS improvement from baseline was 13.62 points at 6 months and 9.82 points at 12 months. Thresholds of substantial clinical benefit that the patient recognizes as a major improvement for the PCS quality-of-life measure following lumbar spine arthrodesis have been established. Suggested substantial clinical benefit thresholds for PCS score are a 6.2-point net improvement or a final raw score of $\geq 35.1$ points. 
Table 2

Summary of SF-36 scores of single-site subjects

\begin{tabular}{|c|c|c|c|c|}
\hline & $\begin{array}{l}\text { Active allograft } \\
N=17\end{array}$ & $\begin{array}{l}\text { Saline } \\
\mathbf{N}=2\end{array}$ & $\begin{array}{l}\text { NSM } \\
N=4\end{array}$ & $\begin{array}{l}\text { Crossover* } \\
N=4\end{array}$ \\
\hline \multicolumn{5}{|c|}{ Mental component score (Mean \pm SD) } \\
\hline Baseline & $42.87 \pm 134.64$ & $40.47 \pm 0.98$ & $46.20 \pm 9.05$ & - \\
\hline Month 3 & - & - & $39 \pm 10.99$ & - \\
\hline Month 6 & $50.28 \pm 9.00$ & $54.08 \pm 1.47$ & - & $55.12 \pm 4.15$ \\
\hline Month 12 & $53.67 \pm 6.81$ & $54.63 \pm 4.45$ & - & $49.01 \pm 11.39$ \\
\hline \multicolumn{5}{|c|}{ Physical component score (Mean \pm SD) } \\
\hline Baseline & $29.03 \pm 5.70$ & $24.74 \pm 7.52$ & $31.63 \pm 3.86$ & - \\
\hline Month 3 & - & - & $27.30 \pm 5,62$ & - \\
\hline Month 6 & $42.65 \pm 10.34$ & $36.64 \pm 23.84$ & - & $49.04 \pm 10.33$ \\
\hline Month 12 & $38.85 \pm 11.66$ & $36.93 \pm 31.50$ & - & $43.88 \pm 7.88$ \\
\hline
\end{tabular}

\section{Clinical outcomes ODI and VAS}

Pain and function responder analyses were conducted post hoc to discriminate between improved and nonimproved patients. VAS for pain and ODI for a condition-specific physical measure before and after intervention were used to assess treatment specific outcomes.

Comparisons were made between response outcomes for the active allograft group from the aggregate data and from the single study site at 12 months to determine likelihood of reproducibility of longer-term results.

Importantly, in comparing the active allograft group from the single site $(n=17)$ against the aggregate $(n=103)$, data from subjects from the single study site were not included in the aggregate responses.

For the active allograft group from aggregate sites, the overall mean reduction in ODI from baseline to 12 months was 27.20 compared with an overall mean reduction of 28.69 in single-site graft recipients. Regarding VAS pain scores, the allograft group of aggregate sites had an overall mean reduction of 33.06 and the single study site had an overall mean reduction of 34.18. A comparison of ODI and VAS outcomes between these 2 groups did not reach statistical significance 12 months post-procedure (Table 3 ). 
Table 3

Change in Visual Analog Scale (VAS) and Oswestry Disability Index (ODI) scores in active allograft subjects from baseline to 12 months

\begin{tabular}{|llll|}
\hline Outcome Tool & Active allograft & Active allograft & p value* \\
& Single site & Other sites & \\
& $\mathbf{N}=17$ & $\mathbf{N}=103$ & \\
\hline VAS average back pain (Mean \pm SD (N) & & & \\
\hline Baseline & $64.35 \pm 18.11(17)$ & $63.85 \pm 18.85(103)$ & - \\
\hline Change from baseline & $-33.06 \pm 29.59(17)$ & $34.18 \pm 27.60(103)$ & 0.875 \\
\hline Oswestry Disability Index (Mean \pm SD (N) & & & - \\
\hline Baseline & $53.6313 .11(16)$ & $51.60 \pm 11.65(103)$ & -813 \\
\hline Change from baseline & $-28.69 \pm 19.16(16)$ & $-27.20 \pm 18.75(103)$ & \\
\hline *P value is derived from the Wilcoxon Rank Sum Test. & & \\
\hline NSM 12- month crossover visit was used. Month 3 value was used as baseline. & \\
\hline
\end{tabular}

\section{MCID Outcomes}

A significant MCID was demonstrated between the allograft and saline group in a planned analysis of ODI responders with $\geq 15$-point reduction. Post hoc analyses included responders with $\geq 20$-point ODI reduction and VAS responders with $\geq 20$-point reduction in pain 12 months post-allograft treatment (Table 4). 
Table 4

Primary efficacy endpoint in average visual analog scale (VAS) and Oswestry Disability Index (ODI) scores in single-site subgroup subjects at 12 months

\begin{tabular}{|c|c|c|c|c|c|c|c|}
\hline & $\begin{array}{l}\text { Active } \\
\text { Allograft } \\
\mathbf{N}=17\end{array}$ & Saline & $\begin{array}{l}\text { Nonsurgical } \\
\text { Management }\end{array}$ & $\begin{array}{l}\text { Overall } \\
\text { p } \\
\text { value* }\end{array}$ & $\begin{array}{l}\text { Allograft } \\
\text { vs. } \\
\text { Saline } \\
\text { p value* }\end{array}$ & $\begin{array}{l}\text { Allograft vs. } \\
\text { Nonsurgical } \\
\text { Management } \\
\text { p value* }\end{array}$ & $\begin{array}{l}\text { Saline vs. } \\
\text { Nonsurgical } \\
\text { Management } \\
\text { p value* }\end{array}$ \\
\hline \multicolumn{8}{|c|}{ VAS average back pain } \\
\hline $\begin{array}{l}\geq 50 \% \\
\text { reduction }\end{array}$ & $\begin{array}{l}47.1 \% \\
(8 / 17)\end{array}$ & $\begin{array}{l}50.0 \% \\
(1 / 2)\end{array}$ & $66.7 \%(2 / 3)$ & $>0.999$ & $>0.999$ & $>0.999$ & $>0.999$ \\
\hline $\begin{array}{l}\geq 15 \\
\text { point } \\
\text { reduction }\end{array}$ & $\begin{array}{l}64.7 \% \\
(11 / 17)\end{array}$ & $\begin{array}{l}50.0 \% \\
(1 / 2)\end{array}$ & $100.0 \%(3 / 3)$ & 0.565 & $>0.999$ & 0.521 & 0.400 \\
\hline $\begin{array}{l}\geq 20 \\
\text { point } \\
\text { reduction }\end{array}$ & $\begin{array}{l}52.9 \% \\
(9 / 17)\end{array}$ & $\begin{array}{l}50.0 \% \\
(1 / 2)\end{array}$ & $100.0 \%(3 / 3)$ & 0.352 & $>0.999$ & 0.242 & 0.400 \\
\hline \multicolumn{8}{|l|}{ ODI } \\
\hline $\begin{array}{l}\geq 10 \\
\text { point } \\
\text { reduction }\end{array}$ & $\begin{array}{l}81.3 \% \\
(13 / 16)\end{array}$ & $\begin{array}{l}100.0 \% \\
(2 / 2)\end{array}$ & $100.0 \%(3 / 3)$ & $>0.999$ & $>0.999$ & $>0.999$ & NA \\
\hline $\begin{array}{l}\geq 15 \\
\text { point } \\
\text { reduction }\end{array}$ & $\begin{array}{l}75.0 \% \\
(12 / 16)\end{array}$ & $\begin{array}{l}100.0 \% \\
(2 / 2)\end{array}$ & $100.0 \%(3 / 3)$ & $>0.999$ & $>0.999$ & $>0.999$ & NA \\
\hline $\begin{array}{l}\geq 20 \\
\text { point } \\
\text { reduction }\end{array}$ & $\begin{array}{l}68.8 \% \\
(11 / 16)\end{array}$ & $\begin{array}{l}50.0 \% \\
(1 / 2)\end{array}$ & $100.0 \%(3 / 3)$ & 0.557 & $>0.999$ & 0.530 & 0.400 \\
\hline \multicolumn{8}{|c|}{${ }^{*} P$ value is derived from Fisher's exact test } \\
\hline \multicolumn{8}{|c|}{ Note: Nonsurgical Management 12-month crossover visit is used. Month 3 value is used as baseline. } \\
\hline
\end{tabular}

Of the active allograft subjects in the aggregate sites ( $n=103$ ), 76.7\% had $\geq 15$-point reduction of ODI from baseline to 12 months. Similarly, $75 \%$ of active allograft subjects from the single study site $(n=17)$ achieved $\geq 15$-point reduction of ODI, showing similarity in MCID. This similarity can also be seen for the responder group characterized by $\geq 20$-point ODI reduction, in which $68.9 \%$ and $68.8 \%$ of active allograft subjects achieved significant pain reduction as seen in the aggregate group and single study site group, respectively. Of the aggregate randomized allograft group, $68.9 \%$ showed $\geq 20$-point reduction in VAS from baseline to 12 months. Similarly, $52.9 \%$ of patients at the single site who received active allograft group showed $\geq 20$-point reduction within the same timeframe.

\section{ODI and VAS Clinical Outcomes from single study site at 24 and 36 months}

Ten subjects from the single site completed their 24-month visit, 9 of whom were from the active allograft group and 1 was from the saline group. At baseline, these 9 active allograft subjects had an average VAS score of 62.11 and average ODI score of 52.44. At 24 months post-treatment, these 9 subjects had an average VAS and 
ODI score of 25.22 and 26.42, showing an average improvement from baseline of 36.89 and 26.02 points, respectively (Figs. 1 and 2). These results indicate sustained improvements in back pain scores and functional outcomes for the allograft treatment arm recipients that were available at follow up. At 24 months, 8 of the 9 active allograft subjects did not receive any secondary disc interventions such as surgery or repeat injections. One of the active allograft subjects did meet the eligibility criteria for a second injection at 24 months.

At the time of this review, 4 active allograft subjects (approximately $40 \%$ of the patients consenting to long-term follow up) from the single site reached and completed their 36-month visit. At 36 months, the 4 subjects had an average VAS score of 13 and average ODI score of 29.44, showing improvements by 51.35 and 25.21 points, respectively from baseline $(n=17)$. This sustained trend from 24 to 36 months is promising, although data is incomplete.

\section{Adverse Events}

The aggregate study had a total of 80 adverse events (AE) across all sites in all treatments. There were 66 events in the active allograft group, 5 in the saline group, 1 in the NSM group, and 8 in the crossover group. Eleven of these 80 events occurred at the single-site subgroup reviewed in this report (Table 5). Of these 11 AEs, 9 events occurred in the active allograft group (52.9\% of 17 subjects), 0 events in the saline group, and 2 events in the crossover group (25\% of 4 subjects). Seven of the 9 adverse events in the active allograft group were related to musculoskeletal and connective tissue disorders. Five of these musculoskeletal AEs were back pain and are common following intradiscal injection $[17,18]$. In the study population, these complaints were self-limited and transient in nature and resolved with the use of non-narcotic pain medications and antispasmodic medications. 
Table 5

Adverse events in single-site subjects

\begin{tabular}{|c|c|c|c|c|c|c|c|c|}
\hline \multirow[b]{2}{*}{ Adverse event } & \multicolumn{2}{|c|}{ Active Allograft } & \multicolumn{2}{|l|}{ Saline } & \multicolumn{2}{|l|}{ NSM } & \multicolumn{2}{|c|}{ Crossover } \\
\hline & $\begin{array}{l}\text { Number } \\
\text { of } \\
\text { events }\end{array}$ & $\begin{array}{l}\text { Number } \\
\text { of } \\
\text { subjects } \\
\text { with } \\
\text { events } \\
\%(N)\end{array}$ & $\begin{array}{l}\text { Number } \\
\text { of } \\
\text { events }\end{array}$ & $\begin{array}{l}\text { Number } \\
\text { of } \\
\text { subjects } \\
\text { with } \\
\text { events } \\
\%(\mathrm{~N})\end{array}$ & $\begin{array}{l}\text { Number } \\
\text { of } \\
\text { events }\end{array}$ & $\begin{array}{l}\text { Number } \\
\text { of } \\
\text { subjects } \\
\text { with } \\
\text { events } \\
\%(N)\end{array}$ & $\begin{array}{l}\text { Number } \\
\text { of } \\
\text { events }\end{array}$ & $\begin{array}{l}\text { Number } \\
\text { of } \\
\text { subjects } \\
\text { with } \\
\text { events } \\
\%(N)\end{array}$ \\
\hline $\begin{array}{l}\text { Musculoskeletal } \\
\text { and connective } \\
\text { tissue disorders }\end{array}$ & 7 & $\begin{array}{l}41.2 \% \\
(7 / 17)\end{array}$ & 0 & $\begin{array}{l}0.0 \% \\
(0 / 2)\end{array}$ & 0 & $\begin{array}{l}0.0 \% \\
(0 / 4)\end{array}$ & 2 & $\begin{array}{l}25.0 \% \\
(1 / 4)\end{array}$ \\
\hline Back pain & 5 & $\begin{array}{l}29.4 \% \\
(5 / 17)\end{array}$ & 0 & $\begin{array}{l}0.0 \% \\
(0 / 2)\end{array}$ & 0 & $\begin{array}{l}0.0 \% \\
(0 / 4)\end{array}$ & 1 & $\begin{array}{l}0.0 \% \\
(0 / 4)\end{array}$ \\
\hline $\begin{array}{l}\text { Intervertebral } \\
\text { disc protrusion }\end{array}$ & 1 & $\begin{array}{l}5.9 \% \\
(1 / 17)\end{array}$ & 0 & $\begin{array}{l}0.0 \% \\
(0 / 2)\end{array}$ & 0 & $\begin{array}{l}0.0 \% \\
(0 / 4)\end{array}$ & 0 & $\begin{array}{l}0.0 \% \\
(0 / 4)\end{array}$ \\
\hline $\begin{array}{l}\text { Muscular } \\
\text { weakness }\end{array}$ & 0 & $\begin{array}{l}0.0 \% \\
(0 / 17)\end{array}$ & 0 & $\begin{array}{l}0.0 \% \\
(0 / 2)\end{array}$ & 0 & $\begin{array}{l}0.0 \% \\
(0 / 4)\end{array}$ & 0 & $\begin{array}{l}25.0 \% \\
(1 / 4)\end{array}$ \\
\hline $\begin{array}{l}\text { Pain in } \\
\text { extremity }\end{array}$ & 1 & $\begin{array}{l}5.9 \% \\
(1 / 17)\end{array}$ & 0 & $\begin{array}{l}0.0 \% \\
(0 / 2)\end{array}$ & 0 & $\begin{array}{l}0.0 \% \\
(0 / 4)\end{array}$ & 0 & $\begin{array}{l}0.0 \% \\
(0 / 4)\end{array}$ \\
\hline $\begin{array}{l}\text { Nervous system } \\
\text { disorders }\end{array}$ & 1 & $\begin{array}{l}5.9 \% \\
(1 / 17)\end{array}$ & 0 & $\begin{array}{l}0.0 \% \\
(0 / 2)\end{array}$ & 0 & $\begin{array}{l}0.0 \% \\
(0 / 4)\end{array}$ & 1 & $\begin{array}{l}25.0 \% \\
(1 / 4)\end{array}$ \\
\hline Hypoaesthesia & 0 & $\begin{array}{l}0.0 \% \\
(0 / 17)\end{array}$ & 0 & $\begin{array}{l}0.0 \% \\
(0 / 2)\end{array}$ & 0 & $\begin{array}{l}0.0 \% \\
(0 / 4)\end{array}$ & 1 & $\begin{array}{l}25.0 \% \\
(1 / 4)\end{array}$ \\
\hline $\begin{array}{l}\text { Lumbar } \\
\text { radiculopathy }\end{array}$ & 1 & $\begin{array}{l}5.9 \% \\
(1 / 17)\end{array}$ & 0 & $\begin{array}{l}0.0 \% \\
(0 / 2)\end{array}$ & 0 & $\begin{array}{l}0.0 \% \\
(0 / 4)\end{array}$ & 0 & $\begin{array}{l}0.0 \% \\
(0 / 4)\end{array}$ \\
\hline $\begin{array}{l}\text { Skin and } \\
\text { subcutaneous } \\
\text { tissue disorders }\end{array}$ & 1 & $\begin{array}{l}5.9 \% \\
(1 / 17)\end{array}$ & 0 & $\begin{array}{l}0.0 \% \\
(0 / 2)\end{array}$ & 0 & $\begin{array}{l}0.0 \% \\
(0 / 4)\end{array}$ & 0 & $\begin{array}{l}0.0 \% \\
(0 / 4)\end{array}$ \\
\hline Rash & 1 & $\begin{array}{l}5.9 \% \\
(1 / 17)\end{array}$ & 0 & $\begin{array}{l}0.0 \% \\
(0 / 2)\end{array}$ & 0 & $\begin{array}{l}0.0 \% \\
(0 / 4)\end{array}$ & 0 & $\begin{array}{l}0.0 \% \\
(0 / 4)\end{array}$ \\
\hline TOTAL & 9 & $\begin{array}{l}52.9 \% \\
(9 / 17)\end{array}$ & 0 & $\begin{array}{l}0.0 \% \\
(0 / 2)\end{array}$ & 0 & $\begin{array}{l}0.0 \% \\
(0 / 4)\end{array}$ & 2 & $\begin{array}{l}25.0 \% \\
(1 / 4)\end{array}$ \\
\hline
\end{tabular}

There were no serious adverse events reported at the single study site. Of the adverse events reported, 4 of the 11 noted at the single site were reported to be possibly related to the allograft or the procedure, or both; 2 were seen in the cross-over group and 2 in the active allograft group. All 4 of these events resolved.

\section{Discussion}

The many treatments for stable discogenic low back pain have been shown to be only marginally effective and often expensive [19-21]. Scientific reviews have shown only modest improvement or no benefit of spine fusion 
over non-surgical treatments in pain and function for patients with discogenic back pain [22-24].

Several preclinical and clinical studies have shown that mesenchymal lineage stromal cells hold great promise in intervertebral disc repair [10,25-27]. These studies have followed evidence of expanded mesenchymal lineages abrogating inflammation as a potential mechanism that further overcame much of the proinflammatory paracrine influence long linked with pain, dysfunction, and degenerative change [27]. The VAST trial represents a departure from these studies in aligning not only a scaffold for cell supplementation but an allogeneic cellular graft intended to provide viable tissue. Although this supports previous work evaluating allograft supplementation studied in preclinical and clinical models [28, 29], graft micronization and delivery with cells represents a unique strategy in this clinical application of disc tissue allograft in the treatment of painful disc degeneration in the lumbar spine. Supplementing tissue loss within the disc augments the biomechanical components of the nucleus pulposus. Doing so may overcome a loading imbalance resulting from degenerative tissue loss and may relieve pain without compromising or restricting spinal segment motion.

Multiple studies have underscored the notion that proper physiological loading is imperative to matrix homeostasis of the intervertebral disc [1,4]. Physiological load stimulates aggrecan production, and improves hydrostatic pressure by structuring water. Allogeneic disc tissue that can retain and bind water through its glycosaminoglycan content may supplement tissue lost to degeneration and may possibly support biomechanical function.

Statistically significant changes in pain and functional outcomes may be meaningful to the patient only if clinically important benefits have been achieved. Several criteria have been devised to quantify clinically important differences, including the minimum clinically important difference (MCID) and clinically important difference (CID).

MCID responder dynamics of patients in this study were carefully considered. Selection of these figures was not arbitrary but MCID criteria for chronic low back pain still lacks consensus after nearly 3 decades [14]. The choice of 15-point MCID based on FDA suggestions in some reports is balanced by other assertions that 10-point improvements are sufficient [30,31]. Clearly, parity between patients contrasting decompression alone or decompression with posterolateral instrumented fusion for treating spondylolisthesis may not translate to the percutaneous supplemental allograft, which was an outpatient procedure and required significantly less rehabilitation after the procedure. Accepting more stringent improvement for a seemingly more innocuous procedure suggests inherent advantages exist without the risks and complications attending bone graft harvest and reoperation rates cited at $10-14 \%$ in the surgical studies [30, 31].

The VAST trial was the first, and largest randomized clinical study to measure the safety and efficacy of viable disc tissue allograft supplementation in the treatment of painful lumbar degenerative disc disease[15, 16]. At 12month follow up, this RCT suggests that viable disc tissue allograft may be a beneficial nonsurgical treatment for patients that have chronically painful lumbar degenerative discs. Subjects treated with viable disc tissue allograft exhibited minimal clinically important difference (MCID) improvements in both functional and pain outcomes based on accepted indices for 15-point improvement of ODI, or 30\% reduction in pain assessed by VAS.

Subjects treated with viable disc tissue allograft exhibited durable improvements in pain and functional outcomes that were consistent and independent of treatment site. With the 24- month and 36-month extension 
for the VAST study, comparisons between this single site subgroup and the aggregate data must be carefully interpreted. Limitations regarding the comparison of the data from a single site with the aggregate data include statistical power for saline and NSM groups. The single site had 2 saline subjects and 4 NSM subjects that crossed over, compared with 17 randomized active allograft subjects. Both saline subjects had stark differences in response. Additional studies are needed to elucidate efficacy of saline clearly among different demographics.

\section{Conclusions}

Comparison of single-site active allograft responses with those of the aggregate data from all sites and subjects showed similar reduction of ODI and VAS scores from baseline to 12 months that reached MCID specified assessment of 15-point reduction in ODI. Early analysis of 24- and 36-month data may suggest that allograft treatment will sustain both efficacy and durability for the available subjects in the aggregate analysis.

\section{Abbreviations}

ODI; Oswestry Disability Index; VAS: Visual Analog Scale; MSC: mesenchymal stem cells; MCID: minimum clinically important difference; VAST: Viable Allograft Supplemented Disc Regeneration in the Treatment of Patients with Low Back Pain With or Without Disc Herniation trial; NSM: nonsurgical management; ODI = Oswestry Disability Index; BMI = Body Mass Index; VAS: visual analog scale; SF-36: Short Form 36; MCS: mental component score; PCS: physical component score; AE: adverse event

\section{Declarations}

\section{Ethics approval and consent to participate}

All patients signed informed consent. Approval for this study was issued by the Sterling Institutional Review Board, Atlanta, Georgia (IRB no. 5792).

\section{Consent for publication}

Not applicable.

\section{Availability of data and materials}

The data used in this study are available from the corresponding author upon reasonable request.

\section{Competing interests}

TD received compensation from Vivex Biologics, Inc. for study-specific data collection, research grants and/or support for Source Healthcare; JKB receives compensation from Vivex Biologics, Inc. for consulting services related and unrelated to the VAST study; AS and TN declare no potential conflicts of interest.

\section{Funding}

VIVEX Biologics, Inc. sponsored this study and contributed to study design, data monitoring, statistical analysis, and reporting of results and paid for independent data collection, core laboratory and EDC services. 
Authors' contributions

TD and JKB contributed to the conception of the study; TD, JKB, AS and TN contributed to the analysis and manuscript preparation and wrote the manuscript. All authors read and approved the final manuscript.

\section{Acknowledgments}

The authors acknowledge the statistical support of Megan Williams of Avania CRO and acknowledge VIVEX Biologics, Inc. for sponsorship of this study. We thank the Hughston Foundation and Carol Binns, MA, for their support in the preparation of this manuscript.

\section{References}

1. Adams MA, Lama P, Zehra U, Dolan P. Why do some intervertebral discs degenerate, when others (in the same spine) do not? Clin Anat. 2015;28:195-204. Epub 2014 Apr 19. PMID: 24753325.

2. Peng BG. Pathophysiology, diagnosis, and treatment of discogenic low back pain. World J Orthop. 2013;4:42-52.

3. Peng B, Pang X. Regeneration and repair of intervertebral disc degeneration. In: Sanders S, editor. Regenerative medicine in China. Washington: Science/AAAS; 2012. pp. 52-53.

4. Vergroesen PP, Kingma I, Emanuel K, Hoogendoorn RJ, Welting TJ, van Royen BJ, et al. Mechanics and biology in intervertebral disc degeneration: a vicious circle. Osteoarthritis Cartilage. 2015;23:1057-1070).

5. Peng B, Fu X, Pang X, Li D, Liu W, Gao C, et al. Prospective clinical study on natural history of discogenic low back pain at 4 years of follow-up. Pain Physician. 2012;15:525-532.

6. Singh K, Ledet E, Carl A. Intradiscal therapy: a review of current treatment modalities. Spine (Phila Pa 1976) 2005;30:S20-S26.

7. Wu T, Song HX, Dong Y, Li JH. Cell-based therapies for lumbar discogenic low back pain: systematic review and single-arm meta-analysis. Spine. 2018;43:49-57.

8. Orozco L, Soler R, Morera C, Alberca M, Sánchez A, García-Sancho J. Intervertebral disc repair by autologous mesenchymal bone marrow cells: a pilot study. Transplantation. 2011;92:822-828.

9. Bae, HW, Amirdelfan K, Coric D, McJunkin TL, Pettine KJ, Hong HJ, et al. A phase II study demonstrating efficacy and safety of mesenchymal precursor cells in low back pain due to disc degeneration. Spine J. 2014;14(11):S31-S32

10. Amirdelfan K, Bae H, McJunkin T, DePalma M, Kim K, Beckworth WJ, et al. Allogeneic mesenchymal precursor cells treatment for chronic low back pain associated with degenerative disc disease: a prospective randomized, placebo-controlled 36-month study of safety and efficacy. Spine J. 2021;21:212-230.

11. Hung M, Saltzman CL, Kendall R, Bounsanga A, Voss MW, Lawrence B, et al. What are the MCIDs for PROMIS, NDI, and ODI instruments among patients with spinal conditions? Clin Orthop Relat Res. 2018;476:2027-2036.

12. Katz NP, Paillard FC, Ekman E. Determining the clinical importance of treatment benefits for interventions for painful orthopedic conditions. Orthop Surg Res. 2015;10:24.

13. Chung AS, Copay AG, Olmscheid N, Campbell D, Walker JB, Chutkan N. Minimum clinically important difference: current trends in the spine literature. Spine (Phila Pa 1976). 2017;42:1096-1105. 
14. Glassman SD, Copay AG, Berven SH, Polly DW, Subach BR, Carreon LY. Defining substantial clinical benefit following lumbar spine arthrodesis. J Bone Joint Surg Am. 2008;90:1839-47.

15. Beall DP, Wilson GL, Bishop R, Tally W. VAST clinical trial: safely supplementing tissue lost to degenerative disc disease. Int J Spine Surg. 2020;14:239-253.

16. Beall DP, Davis T, DePalma M, Amirdelfan K, Yoon E, Wilson GL, et al. Viable disc tissue allograft supplementation; one- and two-level treatment of degenerated intervertebral discs in patients with chronic discogenic low back pain: one-year results of the VAST randomized control trial. Pain Physician. 2021; In press.

17. Guyer RD, Ohnmeiss DD, Vaccaro A. Lumbar discography. Spine J. 2003;3(3 Suppl):11S-27S.

18. Walker J, El Abd O, Isaac Z, Muzin S. Discography in practice: a clinical and historical review. Curr Rev Musculoskel Med. 2008;1:69-83.

19. Kuijpers T, van Middelkoop M, Rubinstein SM, Ostelo R, Verhagen A, Koes BW, et al. A systematic review on the effectiveness of pharmacological interventions for chronic non-specific low-back pain. Eur Spine J. 2011;20:40-50.

20. Benyamin RM, Manchikanti L, Parr AT, Diwan S, Singh V, Falco FJ, et al. The effectiveness of lumbar interlaminar epidural injections in managing chronic low back and lower extremity pain. Pain Physician. 2012;15:E363-E404.

21. Yoshihara $\mathrm{H}$, Yoneoka D. National trends in the surgical treatment for lumbar degenerative disc disease: United States, 2000 to 2009. Spine J. 2015;15:265-71.

22. Fritzell P, Hägg O, Wessberg P, Nordwall A. 2001 Volvo Award Winner in Clinical Studies: Lumbar fusion versus nonsurgical treatment for chronic low back pain: a multicenter randomized controlled trial from the Swedish Lumbar Spine Study Group. Spine (Phila Pa 1976). 2001;26:2521-2532; discussion 2521-2532.

23. Qaseem A, Wilt TJ, McLean RM, Forciea MA. Clinical Guidelines Committee of the American College of Physicians. Noninvasive treatments for acute, subacute, and chronic low back pain: a clinical practice guideline from the American College of Physicians. Ann Intern Med. 2017;166:514-30.

24. Bydon M, De la Garza-Ramos R, Macki M, Baker A, Gokaslan AK, Bydon A. Lumbar fusion versus nonoperative management for treatment of discogenic low back pain: a systematic review and metaanalysis of randomized controlled trials. J Spinal Disord Tech. 2014;27:297-304.

25. Schol J, Sakai D. Cell therapy for intervertebral disc herniation and degenerative disc disease: clinical trials. Int Orthop. 2019;43:1011-25.

26. Sun Y, Leung VY, Cheung KM. Clinical trials of intervertebral disc regeneration: current status and future developments. Int Orthop. 2019;43:1003-10.

27. Ruan D, He Q, Ding Y, Hou L, Li J, Luk KD. Intervertebral disc transplantation in the treatment of degenerative spine disease: a preliminary study. Lancet. 2007;369:993-99.

28. Werner BC, Li X, Shen FH. Stem cells in preclinical spine studies. Spine J. 2014;14(3):542-51.

29. Nomura T, Mochida J, Okuma M, Nishimura K, Sakabe K. Nucleus pulposus allograft retards intervertebral disc degeneration. Clin Orthop Relat Res. 2001;(389):94-101.

30. Hägg $\mathrm{O}$, Fritzell P, Nordwall A. The clinical importance of changes in outcome scores after treatment for chronic low back pain. Eur Spine J. 2003;12:12-20 
31. Ghogawala Z, Resnick DK, Watters WC 3rd, Mummaneni PV, Dailey AT, Choudhri TF, et al. Guideline update for the performance of fusion procedures for degenerative disease of the lumbar spine - part 2: assessment of functional outcome following lumbar fusion. J Neurosurg Spine. 2014;21:7-13.

\section{Figures}

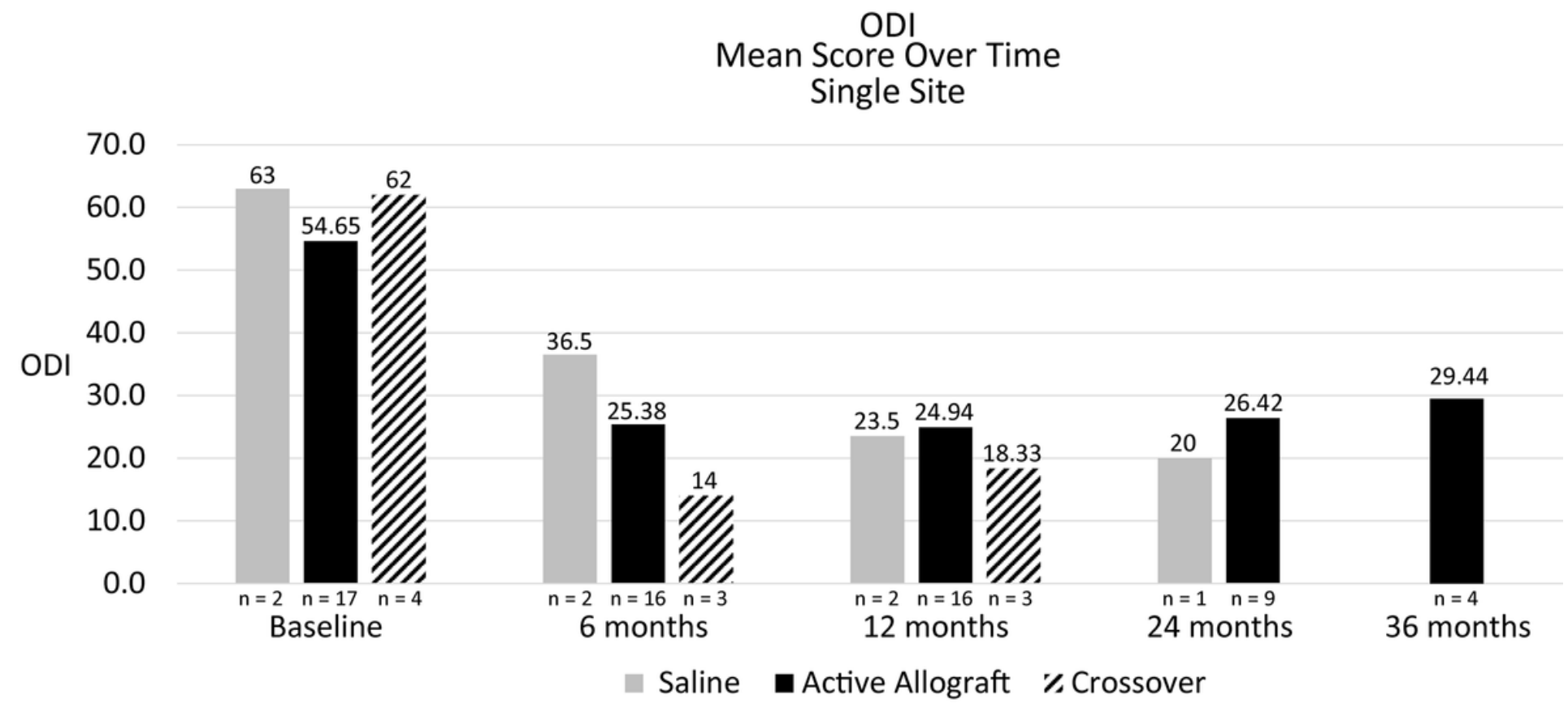

Figure 1

Mean Oswestry Disability Index (ODI) scores over time from the single-site subgroup.

\section{VAS Average Back Pain \\ Mean Score Over Time \\ Single Site}

100.0

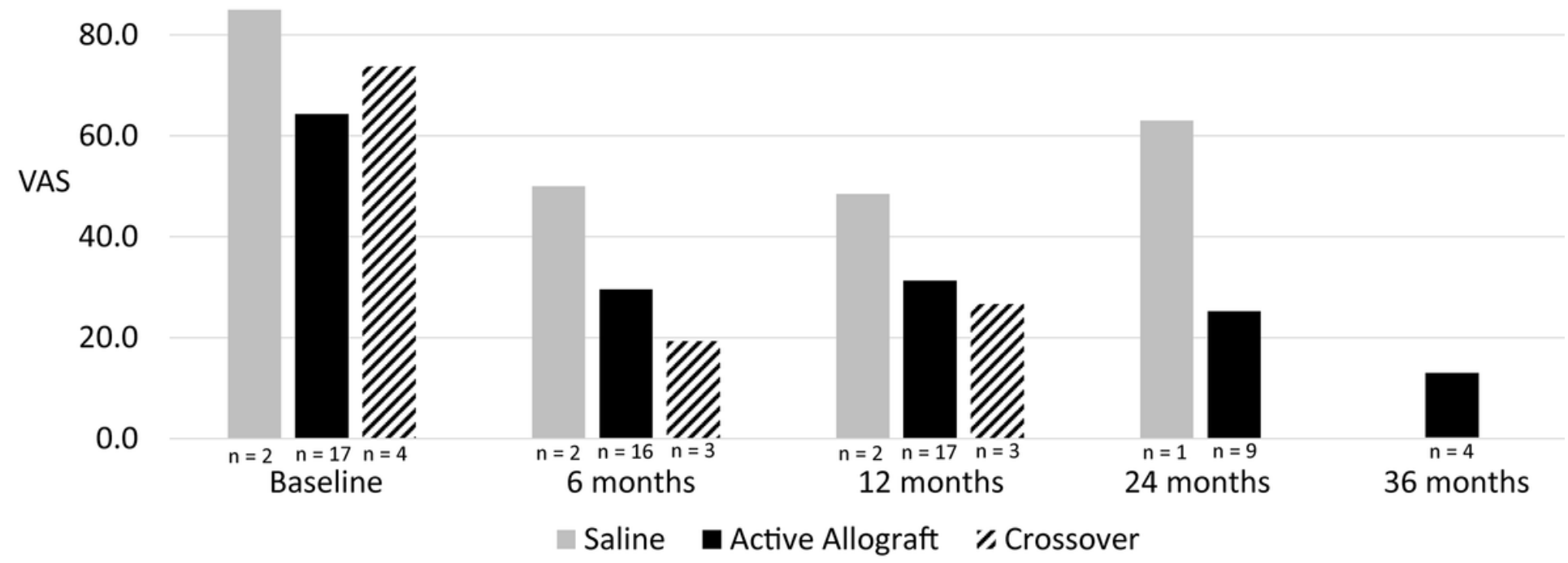


Figure 2

Mean Visual Analog Scale (VAS) scores over time from the single-site subgroup. 